\title{
Collections Support Services (CSS) - 25 Years of Improving Access and Care to our Nation's Collections
}

\author{
Leslie Schuhmann ${ }^{\ddagger}$, Christine G Chagnon ${ }^{\ddagger}$ \\ ‡ Smithsonian Institution, Washington DC, United States of America
}

Corresponding author: Leslie Schuhmann (schuhmannl@si.edu), Christine G Chagnon (geerc@si.edu)

Received: 16 Apr 2018 | Published: 13 Jun 2018

Citation: Schuhmann L, Chagnon C (2018) Collections Support Services (CSS)- 25 Years of Improving Access and Care to our Nation's Collections. Biodiversity Information Science and Standards 2: e25889.

https://doi.org/10.3897/biss.2.25889

\begin{abstract}
Originally formed in the early 1980 s as the Move Crew to move museum collections to the newly opened state of the art Smithsonian Institution's Museum Support Center, Collections Support Services has evolved into a team of highly skilled museum professionals recognized as trusted experts, innovators, project managers, and problem solvers in all aspects of collections stewardship. We have packed, moved, and stored MILLIONS of objects across Smithsonian museums including the National Museum of Natural History and several of our art museums; the Freer Sackler Gallery, Hirshhorn Museum and Sculpture Garden, and National Museum of African Art.
\end{abstract}

Our vast experience with Natural History collections has been with objects ranging from microscopic invertebrates, fragile bird eggs, 40' war canoes, whale skulls, giant squids and EVERYTHING in between! Many of these collections came from overcrowded and dusty attics, basements, and warehouses prone to flooding, pest infestation, and poor climate control. We have spent the last 25 years moving these collections into our climate controlled storage pods furnished with new metal cabinets designed for long term preservation. Some of the unique packing and transportation methods we will highlight in this presentation are "airbags" that encompass fragile bird skeletons and uniform shipping containers made of ethafoam planks and old wooden drawers. In addition, we have 
designed and constructed aluminum pallets for oversized collections, specialized elephant skull pallets, and plaster jackets for paleo fossil specimens. These storage solutions have greatly improved access to collections by allowing researchers to study specimens with minimal handling necessary. This presentation will specifically demonstrate these and other dramatic improvements that we have made as well as highlight innovative solutions we developed to safely transport, store, and provide better access to our Natural History collections for future generations.

\section{Keywords}

collections, handling, stewardship, access, transport, storage

\section{Presenting author}

Leslie Schuhmann and Christine G Chagnon 